\title{
Circulating Proprotein Convertase Subtilisin/Kexin Type 9 (PCSK9) Concentration and Risk of Cardiovascular Events - Systematic Review and Meta-Analysis of Prospective Studies -
}

\author{
Yunjun Xiao, MD; Chaoqiong Peng, BSc; Wei Huang, BSc; Jinzhou Zhang, BSc; \\ Yang Gao, PhD; Jean H. Kim, MD; Eng-kiong Yeoh, MD; Xuefen Su, PhD
}

\begin{abstract}
Background: Previous studies have not found a consistent association between circulating proprotein convertase subtilisin/kexin type 9 (PCSK9) and the risk of cardiovascular events. The aim of this meta-analysis was to evaluate this association in prospective studies.

Methods and Results: A systematic search of prospective studies published through October 2016 was carried out in order to identify studies that met pre-specified inclusion criteria. After independent data extraction, summary relative risks were calculated using random-effects models. On meta-analysis of 6 cohort and 1 nested case-control study, circulating PCSK9 concentration as a continuous variable was not significantly associated with the risk of cardiovascular events (overall RR, 1.12; 95\% Cl: 0.98-1.29; $\mathrm{P}=0.09)$, with significant heterogeneity $\left(I^{2}=55.1 \%\right.$, Pheterogeneity $\left.=0.038\right)$. The highest but not middle categories of circulating PCSK9 was significantly associated with the risk of cardiovascular events. On subgroup analysis of study design, mean age at baseline, sample size, follow-up time, and pre-existing disease, there was no significant association between PCSK9 and cardiovascular events. Sensitivity analysis with various exclusion and inclusion criteria did not materially change the results.
\end{abstract}

Conclusions: Circulating PCSK9 concentration as a continuous variable was not significantly associated with the risk of cardiovascular events. More well-designed studies are needed to clarify the role of PCSK9 in cardiovascular risk.

Key Words: Cardiovascular; Event; Meta-analysis; Proprotein convertase subtilisin/kexin type 9 (PCSK9); Prospective study

$\mathbf{T}$ he proprotein convertase subtilisin/kexin type 9 (PCSK9) enzyme plays an essential role in regulating cholesterol homeostasis. PCSK9 enhances the endosomal and lysosomal degradation of hepatic lowdensity lipoprotein (LDL) receptor (LDL-R), resulting in increased serum LDL cholesterol (LDL-C) concentration. ${ }^{1-3}$

Mutations in PCSK9 can influence circulating PCSK9 level. ${ }^{4}$ The coding gene of human PCSK9 protein is located on chromosome $1 \mathrm{p} 32.3$; it encompasses 12 exons and encodes a 692-amino acid glycoprotein. To date, 163 mutations in PCSK9 have been identified, involving both gain of function and loss of function. Mutations in PCSK9 have been shown to be associated with LDL-C and cardiovascular disease (CVD) in large-scale genome-wide association studies. 5 ,6 Hence, PCSK9 has emerged as a novel attractive target in lowering LDL-C. Currently, statins are

\section{Editorial p 1098}

the recommended first-line agents for lowering LDL-C but may increase plasma PCSK9, whereas statins combined with PCSK9 inhibitors may counteract the effect of increased PCSK9., In recent years, some early phase clinical trials have shown that PCSK9 inhibitors can reduce plasma LDL-C in patients with familial and non-familial hypercholesterolemia and yield the expected reduction in CVD events without major adverse effect.9,10 PCSK9 reduction may also be beneficial to the other lipids and lipoproteins, such as total cholesterol, triglycerides, and high-density lipoprotein cholesterol.

Despite these findings, whether plasma PCSK9 level accurately predicts the risk of cardiovascular events, inde-

Received November 9, 2016; revised manuscript received February 20, 2017; accepted March 2, 2017; released online April 11, 2017 Time for primary review: 18 days

Department of Nutrition and Food Hygiene, Shenzhen Center for Disease Control and Prevention, Shenzhen (Y.X., C.P., W.H., J.Z.); Department of Physical Education, Hong Kong Baptist University, Hong Kong (Y.G.); School of Public Health and Primary Care, Faculty of Medicine, Chinese University of Hong Kong, Hong Kong (J.H.K., E.-k.Y., X.S.); and The Chinese University of Hong Kong Shenzhen Research Institute, Shenzhen (X.S.), China

Mailing address: Xuefen Su, ScD, MPH, School of Public Health and Primary Care, Faculty of Medicine, Room 508, School of Public Health, Prince of Wales Hospital, The Chinese University of Hong Kong, Shatin, New Territories, Hong Kong, China. E-mail: xuefensu@cuhk.edu.hk or Yunjun Xiao, MD, Department of Nutrition and Food Hygiene, Shenzhen Center for Disease Control and Prevention, Longyuan Road No 8, Nanshan District, Shenzhen, China. E-mail: xyjszcdc@163.com

ISSN-1346-9843 All rights are reserved to the Japanese Circulation Society. For permissions, please e-mail: cj@j-circ.or.jp 
pendent of its effects on LDL-C concentration, remains controversial. The inconsistent results across different studies may have resulted from different measurement methods of plasma PCSK9, variations in study design or differences in clinical outcome. In order to use PCSK 9 as a suitable biomarker in CVD prevention trials, it is important to clarify the role of circulating PCSK9 in independently predicting cardiovascular events beyond LDL-C. To address this knowledge gap, we performed a metaanalysis of prospective studies to investigate the pleiotropic effect of circulating PCSK9 level on risk of cardiovascular events by calculating a summary risk estimate.

\section{Methods}

\section{Data Sources and Literature Search}

This study followed the guidelines of the Meta-analysis of Observation Studies in Epidemiology group. ${ }^{11}$ Databases including PubMed, EMBASE, OVID, Google Scholar, and Cochrane Library were searched through October 2016 for relevant articles that reported the association between circulating PCSK9 level and the risk of cardiovascular events. To avoid missing any relevant study, we also searched the references of retrieved papers and recent reviews in the field. The following medical subject headings (MESH) and key words were used in the literature search: "proprotein convertase subtilisin/kexin type 9", or "PCSK9", or "neural apoptosis regulated convertase-1", or "NARC-1", and "CVD", or "cardiovascular events", or "coronary disease", or "myocardial infarction", or "myocardial ischemia", or "coronary stenosis", "coronary restenosis", or "cerebrovascular disorders", or "stroke", or "heart failure", or "death", "mortality", or "all-cause mortality", or "cardiovascular mortality", and "cohort studies", or "prospective studies", or "follow-up studies". No restrictions were imposed. English and non-English articles were included in the search strategy.

\section{Study Selection}

Two reviewers independently screened the titles and abstracts of the searched papers and excluded the articles if they did not clearly study the association between PCSK9 and CVD events using a prospective design. The same 2 reviewers also independently evaluated the remaining full-text articles to assess the study eligibility on the basis of a predefined set of criteria. The inclusion criteria were as follows: (1) full-text study, published prospective cohort or nested case-control study; (2) plasma or serum PCSK9 concentration as exposure of interest; (3) all-cause or cardiovascular mortality or CVD events, myocardial infarction, stroke, or heart failure as outcome of interest; and (4) calculation of relative risk (RR) and the corresponding $95 \%$ CI or provision of sufficient data to calculate them. Disagreements on study eligibility were resolved by discussion.

\section{Data Extraction and Quality Assessment}

The key exposure variable was circulating PCSK9 concentration at baseline. PCSK9 was measured using enzymelinked immunosorbent assay (ELISA) kit. With the exception of 1 study, ${ }^{12}$ most studies on the incidence of cardiovascular events reported circulating PCSK9 as a continuous variable. Four studies on cardiovascular events reported PCSK9 as a categorical variable. In the present meta-analysis PCSK9 was used as both a continuous and as a categorical variable.

Outcomes of interest in this meta-analysis included CVD events, defined as fatal and non-fatal coronary artery disease (CAD), fatal and non-fatal stroke, cardiac arrest, heart failure, peripheral artery disease, and sudden death. CAD was defined as acute myocardial infarction, angina pectoris, and other ischemic heart disease.

Two reviewers independently abstracted data on study characteristics and results using a standardized data collection form. Discrepancies in data extraction between reviewers were resolved by consensus. Data extracted included: first author's last name; year of publication; country of origin; study period and duration of follow-up; subject characteristics and age at baseline; number of CVD events, and total number of participants; PCSK9 measurement methods; assessment of outcomes; RR, hazard ratios (HR), OR or incidence density ratio; and adjusted variables. We also systematically assessed the study quality. Briefly, a 9-point system based on the Newcastle Ottawa Scale was used to assess study quality. Each study was evaluated on 3 broad criteria: (1) subject selection; (2) comparability of the subjects; and (3) ascertainment of the exposure or outcome of interest. Two reviewers independently assessed the quality of each study. Disagreements were resolved through discussion to reach a consensus. Studies that scored $\geq 7$ (out of a maximum 9 points) were considered to be high quality.

\section{Statistical Analysis}

Relative risk was used as a common measure of the association between PCSK9 and the risk of CVD events. HR and incidence density ratios were considered as estimates of RR. RR and corresponding standard errors (SE), which were derived from $95 \%$ CI or P-values, were logarithmically transformed for the studies in which the distribution of circulating PCSK9 was skewed, to stabilize variance and normalize the distribution. ${ }^{13}$ To calculate summary RR and its $95 \% \mathrm{CI}$, we pooled the results using a randomeffects models. ${ }^{14}$ The random-effects model was chosen a priori because of the anticipated clinical heterogeneity and because it is considered as more conservative than the fixed-effects model, because it accounts for both withinand between-study heterogeneity. ${ }^{15}$ Heterogeneity across studies was evaluated using the $\mathrm{Q}$ statistic with a conservative $\mathrm{P}=0.10$. We also calculated the $\mathrm{I}^{2}$ statistic, which describes the total variation across studies attributable to heterogeneity rather than chance; $\mathrm{I}^{2}>50 \%$ indicates at least moderate heterogeneity. ${ }^{16} \mathrm{We}$ assessed the influence of each individual study on the overall risk estimate by excluding 1 study at a time. Because participant characteristics, PCSK9 measurement, and adjustments for confounding factors were not consistent across studies, we further conducted several sensitivity and stratified analyses to explore possible sources of heterogeneity and to examine the influence of various inclusion criteria on the overall risk estimate. Stratified analysis was also carried out for age, number of total participants, duration of follow-up, and presence of pre-existing CAD. Because statins influence PCSK9 concentration, we analyzed the effect of PCSK9 on the risk of CVD events according to statin status. Sensitivity analysis was also carried out for studies with the same ELISA kits for PCSK9 measurement. Potential publication bias was evaluated on visual inspection of the Begg funnel plots in which log RR were plotted against their SE. Begg rank correlation test and Egger 


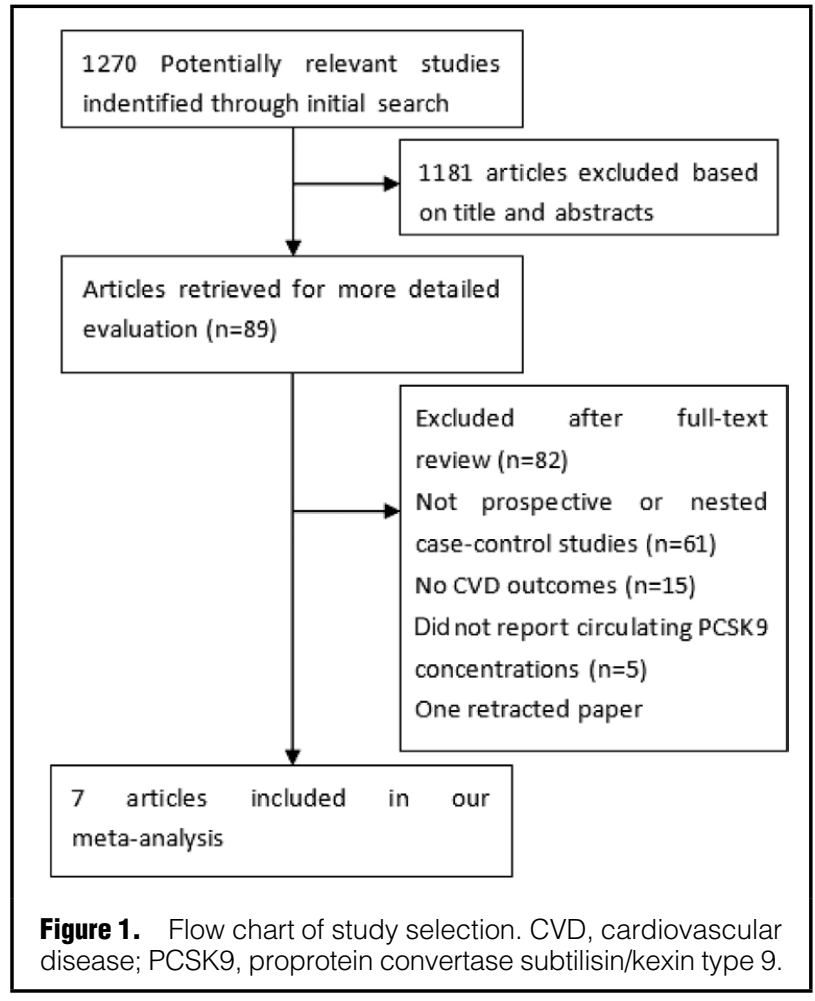

linear regression test were also carried at the $\mathrm{P}<0.10$ level. ${ }^{17,18}$ All analysis was performed using STATA version 11.0 (Stata Corp LP, College Station, TX, USA). $\mathrm{P}<0.05$ was considered statistically significant, except where otherwise specified.

\section{Results}

\section{Study Selection}

Of the 1,270 reports retrieved from the initial search, we excluded 1,181 studies unrelated to the association between PCSK9 and the risk of CVD events after first screening based on abstracts or titles. A full-text review of the remaining 89 papers further excluded 61 studies that were not prospective cohort studies or nested case-control studies. Fifteen studies that did not report CVD outcomes and an additional 5 studies that did not report circulating PCSK 9 concentration were also excluded. Furthermore, a retracted paper that reported PCSK9 and CVD outcomes was also excluded. ${ }^{19}$ Seven studies were ultimately included in the present meta-analysis (Figure 1).

\section{Study Characteristics}

Table 1 lists the characteristics of the 7 prospective studies including 6 cohort $^{20-25}$ and 1 nested case-control study. ${ }^{12}$ These studies were published between 2014 and 2016 from different countries. The subject age range was 49.4 to 68 years old. One study was limited to male respondents; ${ }^{22}$ another was conducted in women only, ${ }^{\mathbf{1 2}}$ and the other 5 studies reported combined results for both men and women. The mean length of follow-up ranged from 1 to 17 years. Study sample size ranged from 443 to 4,232 (total, $10,068)$. Of the 6 cohort studies, 1 study was conducted in patients with chronic kidney disease, ${ }^{25} 1$ among community-based adults, ${ }^{24} 3$ in CAD patients, and 1 in male fire- fighters. ${ }^{22}$ Mean PCSK9 in these 6 studies was $303 \mathrm{ng} / \mathrm{mL}$ and ranged from 94.3 to $546.5 \mathrm{ng} / \mathrm{mL}$. Of the 7 studies included, only 1 reported all-cause mortality, ${ }^{23}$ and the other studies reported CVD events including similar CVD outcomes. None of the 7 studies, however, reported associations between PCSK9 and the risk of discrete CVD events (e.g., cardiovascular mortality, myocardial infarction, stroke, or heart failure). CVD outcomes were assessed using a variety of sources, including medical records, death certificates, and hospital database. All the studies were adjusted for a group of conventional cardiovascular risk factors, and the RR or HR from the model adjusted for the maximum number of risk factors were used to calculate summary estimates. The quality of the included 8 studies was high; 2 studies scored a maximum of 9 points and the other 5 studies scored 8 points, using the Newcastle-Ottawa Scale evaluation system (Table 1).

\section{Circulating PCSK9 as a Continuous Variable}

Figure 2 presents the results from the random-effects model combining the RR for the risk of CVD events. RR varied from 0.33 to 1.48 across the different studies but only one of the 7 studies showed a significantly positive association between PCSK9 and the risk of CVD events (RR, 1.48; 95\% CI: $1.12-1.95 ; \mathrm{P}<0.001) .{ }^{24}$ Overall, circulating PCSK9 concentration as a continuous variable was not significantly associated with the risk of CVD events (RR, 1.12; 95\% CI: 0.98-1.29, $\mathrm{P}=0.09$ ). Significant heterogeneity across the studies was observed $\left(\mathrm{I}^{2}=55.1 \%\right.$, Pheterogeneity $\left.=0.038\right)$. Stratified analysis by study design shows similar results. The combined RR was 1.12 (95\% CI: 0.97-1.31, P=0.117) in the 6 cohort studies, with moderate heterogeneity $\left(\mathrm{I}^{2}=61.5 \%\right.$, Pheterogeneity $\left.=0.023\right)$. Similarly, the association between PCSK9 and the risk of CVD events in the 1 nested case-control study was also not significant (RR, 1.15; 95\% CI: $0.74-1.79, \mathrm{P}=0.535)$.

\section{Circulating PCSK9 as a Categorical Variable}

The association between PCSK9 and the risk of CVD events was further analyzed using results from the 3 studies that assessed this association using PCSK9 as a categorical variable. Among the 3 studies, 2 divided PCSK9 into quartiles, and the other used tertiles. We first combined the HR of quartiles 2 and 3 from the 2 quartile studies into the middle PCSK 9 category. Then, we calculated the summary HR for the middle and highest PCSK9 categories, respectively, in relation to the risk of CVD events, with the lowest category as the reference. The combined RR for the risk of CVD events from the random-effects models are shown in Figure 3. Overall, there was no significant association between the middle PCSK9 category and the risk of CVD events (RR, 1.07; 95\% CI: 0.89-1.29, P=0.485; $\mathrm{I}^{2}=26.2 \%$, $\left.P_{\text {heterogeneity }}=0.258\right)$. The highest PCSK9 category, however, was significantly associated with the risk of CVD events (RR, 1.38; 95\% CI: 1.12-1.72, $\mathrm{P}=0.003$; $\mathrm{I}^{2}=0.0 \%$, Pheterogeneity $=0.636)$.

\section{Stratified and Sensitivity Analyses}

The overall combined RR were not significant when stratified according to mean age ( $\leq 60$ and $>60$ years), sample size $(<1,000$ and $>1,000)$, duration of follow-up ( $\leq 4$ and $>4$ years), and presence of pre-existing CAD. The association between PCSK9 and the risk of CVD events was stronger in studies with sample size $>1,000$ (RR, 1.08; 95\% CI: $1.00-1.15)$ than in studies with $<1,000$ participants $(R R$, 
Table 1. Circulating PCSK9 and Risk of CVD Events: Characteristics of 7 Prospective Studies

\begin{tabular}{|c|c|c|c|c|c|}
\hline \multirow[t]{2}{*}{ Source } & \multirow{2}{*}{$\begin{array}{l}\text { Location } \\
\text { and study } \\
\text { design }\end{array}$} & \multirow[t]{2}{*}{ Subjects } & \multirow[t]{2}{*}{$\begin{array}{l}\text { Sex/age } \\
\text { (years) }\end{array}$} & $\begin{array}{c}\text { PCSK9 } \\
\text { concentration } \\
(\mathrm{ng} / \mathrm{mL}) \\
\end{array}$ & \multirow[t]{2}{*}{$\begin{array}{c}\text { Duration } \\
\text { (years) }\end{array}$} \\
\hline & & & & $\begin{array}{l}\text { Median } \\
\text { (range) }\end{array}$ & \\
\hline $\begin{array}{l}\text { Leander } \\
\text { et al } \\
(2016)^{24}\end{array}$ & $\begin{array}{l}\text { Sweden, } \\
\text { cohort }\end{array}$ & $\begin{array}{c}4,232 \\
\text { population- } \\
\text { based adults }\end{array}$ & $\begin{array}{c}\mathrm{M} / \mathrm{F} \\
60 \text {-year-olds }\end{array}$ & $\begin{array}{c}94.3 \\
(73.1-122.3)\end{array}$ & 15 \\
\hline $\begin{array}{l}\text { Li et al } \\
(2015)^{21}\end{array}$ & $\begin{array}{l}\text { China, } \\
\text { cohort }\end{array}$ & $\begin{array}{c}616 \\
\text { patients with } \\
\text { stable CAD }\end{array}$ & $\begin{array}{c}M / F \\
57.88 \pm 9.82\end{array}$ & $\begin{array}{c}230.11 \\
(190.45-277.83)\end{array}$ & 1.5 \\
\hline
\end{tabular}

Adjusted

risk factors

Outcomes

Quality

Sex, LDL-C, HDL-C, CVD events: fatal or lipoprotein(a), triglycer- non-fatal MI, angina ides, hypertension, DM, pectoris, chronic ischobesity, overweight physical inactivity, current smoking, and statin use. emic heart disease sudden cardiac death, and fatal or non-fatal ischemic stroke.

Age, sex, BMI, hypertension, diabetes

MACE: cardiac death stroke, MI, postdischarge revascularhypo-HDL cholesterol- ization, or unstable emia, current smoking, angina. family history of CAD, uric acids, and hs-CRP.

$\begin{array}{lccccc}\begin{array}{l}\text { Rogacev } \\ \text { et al }\end{array} & \begin{array}{c}\text { Germany, } \\ \text { cohort }\end{array} & \begin{array}{c}443 \text { CKD } \\ \text { patients }\end{array} & \begin{array}{c}\text { M/F 67.7 } \\ (57.0-74.3)\end{array} & \begin{array}{c}343 \\ (270-413)\end{array} & 3.0 \\ (2016)^{25} & & & & & \end{array}$

Age, GFR, total Acute Ml; surgical or cholesterol, Apo A-I, Apo $B$ and mean BP, gender, prevalent CVD and DM, statin intake.

interventional coronary/ cerebrovascular/ peripheral-arterial revascularization; stroke with symptoms $\geq 24 \mathrm{~h}$, amputation above the ankle; or death from any cause.

\begin{tabular}{|c|c|c|c|}
\hline Gencer & Switzerland, & 2,030 ACS & $\begin{array}{c}\mathrm{M} / \mathrm{F} \\
\end{array}$ \\
\hline
\end{tabular}

\begin{tabular}{|c|c|}
\hline $\begin{array}{l}\text { et al } \\
(2016)^{23}\end{array}$ & cohort \\
\hline
\end{tabular}

$63.6 \pm 12.5 \quad(374-396)$

1 Cardiovascular risk factor (sex, history of hypertension, history of DM, smoking status, baseline total cholesterol, and baseline use of statin). GRACE (ST-segment deviation, death or recurrent MI age, heart rate, SBP, creatinine, Killip class, cardiac arrest at admission, and

All-cause death (cardiac, vascular, and non-cardiovascular) major adverse cardiovascular events: cardiac death or recurrent $\mathrm{Ml}$ events, cardiac or stroke events, cardiac death or recurrent MI or coronary revascularization elevated biomarkers of events. necrosis).

\begin{tabular}{|c|c|c|c|c|c|c|c|c|}
\hline $\begin{array}{l}\text { Zhu et al } \\
(2015)^{22}\end{array}$ & $\begin{array}{l}\text { Canada, } \\
\text { cohort }\end{array}$ & $\begin{array}{l}1,527 \text { male } \\
\text { firefighters }\end{array}$ & M 49.4 \pm 9.9 & $\begin{array}{c}286 \\
(231-355)\end{array}$ & 7.2 & $\begin{array}{l}\text { Age, Framingham risk } \\
\text { score, metabolic } \\
\text { syndrome, DM, fasting } \\
\text { glucose, insulin, } \\
\text { hypertension, current } \\
\text { smoking status, family } \\
\text { history, on hyperten- } \\
\text { sion medication, on } \\
\text { statin therapy, waist } \\
\text { circumference, BMI, } \\
\text { total cholesterol, } \\
\text { HDL-C, LDL-C, triglyc- } \\
\text { erides, hs-CRP. }\end{array}$ & $\begin{array}{l}\text { Composite of cardio- } \\
\text { vascular death; resus- } \\
\text { citated cardiac arrest; } \\
\text { non-fatal Ml; revascu- } \\
\text { larization in the coro- } \\
\text { nary, carotid, or periph- } \\
\text { eral circulation; } \\
\text { symptomatic vascular } \\
\text { disease with }>50 \% \\
\text { stenosis; and inci- } \\
\text { dences of stroke or } \\
\text { transient ischemic } \\
\text { attack. }\end{array}$ & 8 \\
\hline $\begin{array}{l}\text { Werner } \\
\text { et al } \\
(2014)^{20}\end{array}$ & $\begin{array}{l}\text { Germany, } \\
\text { cohort }\end{array}$ & $\begin{array}{l}504 \text { consecutive } \\
\text { patients who had } \\
\text { a documented } \\
\text { clinically stable } \\
\text { CAD }\end{array}$ & $\begin{array}{l}\mathrm{M} / \mathrm{F} 68 \\
(59-74)\end{array}$ & $\begin{array}{c}546.5 \\
(471-622)\end{array}$ & 4 & $\begin{array}{l}\text { Age, gender, risk } \\
\text { factors, medication, } \\
\text { glucose metabolism } \\
\text { and lipids. }\end{array}$ & $\begin{array}{l}\text { Cardiovascular death } \\
\text { and cardiovascular } \\
\text { hospitalization for ACS } \\
\text { or hospitalization for } \\
\text { unplanned, symptom- } \\
\text { induced coronary angi- } \\
\text { ography and coronary } \\
\text { revascularization. }\end{array}$ & 8 \\
\hline $\begin{array}{l}\text { Ridker } \\
\text { et al } \\
(2016)^{12}\end{array}$ & $\begin{array}{l}\text { USA, nested } \\
\text { case-control }\end{array}$ & $\begin{array}{l}358 \text { first ever } \\
\text { cardiovascular } \\
\text { events case and } \\
358 \text { control }\end{array}$ & $\begin{array}{c}F 63 \\
(58-68)\end{array}$ & $\begin{array}{c}299.7 \\
(252.9-358.8)\end{array}$ & 17 & $\begin{array}{l}\text { Age, smoking, and } \\
\text { HRT. }\end{array}$ & $\begin{array}{l}\text { First ever cardiovascu- } \\
\text { lar events: MI, throm- } \\
\text { boembolic stroke, or } \\
\text { cardiovascular death. }\end{array}$ & 9 \\
\hline
\end{tabular}

ACS, acute coronary syndrome; Apo, apolipoprotein; BMI, body mass index; BP, blood pressure; CAD, coronary artery disease; CKD, chronic kidney disease; CVD, cardiovascular disease; DM, diabetes mellitus; GFR, glomerular filtration rate; GRACE, Global Registry of Acute Coronary Events; HDL-C, high-density lipoprotein cholesterol; HRT, hormone replacement therapy; hs-CRP, high-sensitivity C-reactive protein; LDL-C, low-density lipoprotein cholesterol; MACE, major adverse cardiovascular events; MI, myocardial infarction; PCSK9, proprotein convertase subtilisin/kexin type 9; SBP, systolic blood pressure. 


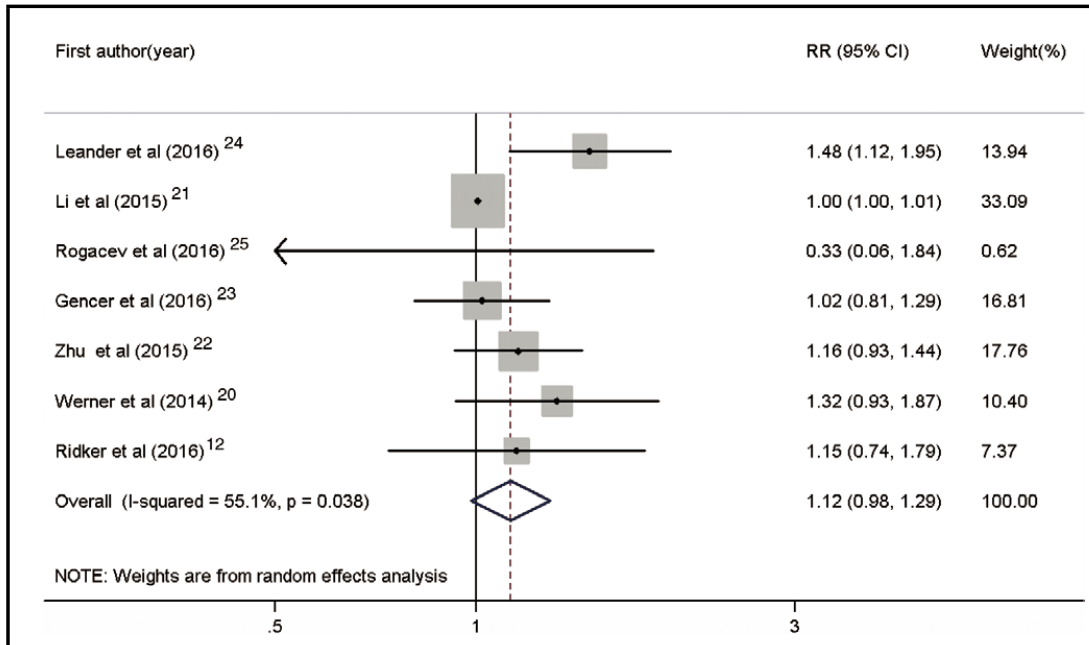

Figure 2. Random-effects model combining the relative risk (RR) for cardiovascular disease events and circulating proprotein convertase subtilisin/kexin type 9 as a continuous variable.

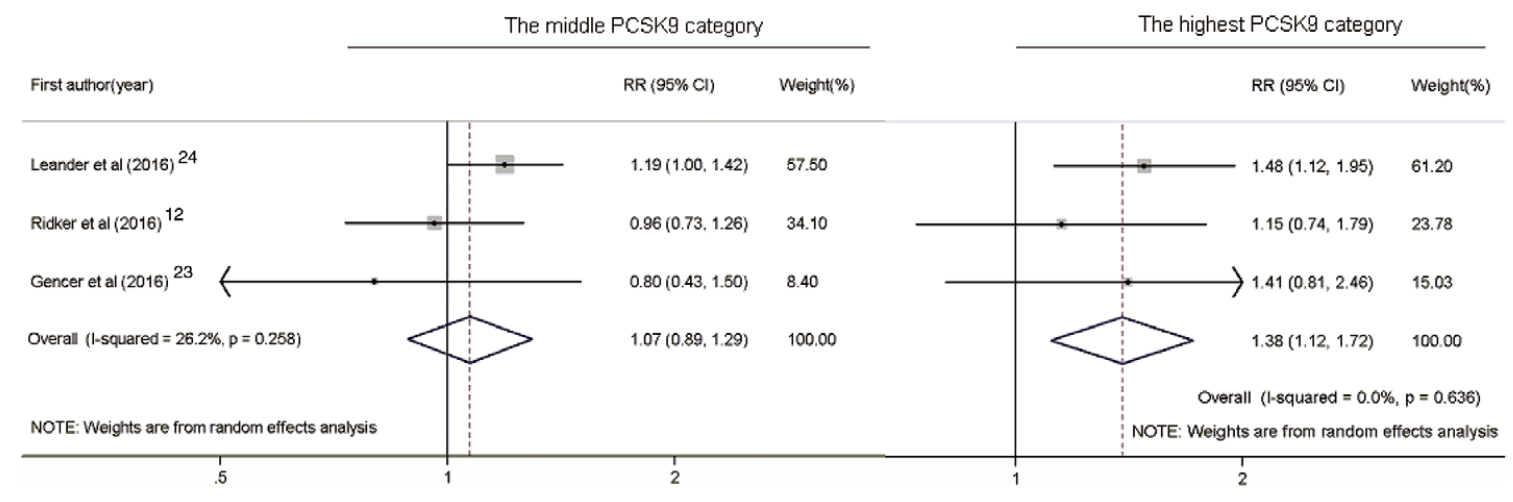

Figure 3. Association between high and middle circulating proprotein convertase subtilisin/kexin type 9 (PCSK9) levels and risk of cardiovascular disease (CVD) events. RR, relative risk.

1.04; 95\% CI: $0.83-1.25$ ) and in studies with follow-up $>4$ years than in those $\leq 4$ years (follow-up $>4$ years: $R R, 1.08$; 95\% CI: $1.00-1.17$; follow-up $\leq 4$ years: RR, $1.01 ; 95 \%$ CI: 0.89-1.14). No significant effect of PCSK9 on CVD risk was observed with regard to statins status (Table 2).

Sensitivity analysis was also conducted with different inclusion criteria. Werner et al found that PCSK9 was significantly associated with the risk of CVD events in the model unadjusted for fasting triglyceride concentration (RR, 1.44; 95\% CI: $1.02-2.04 ; \mathrm{P}=0.038){ }^{20}$ The association, however, became non-significant after adjustment for fasting triglyceride concentration (RR, $1.32 ; 95 \% \mathrm{CI}$ : $0.93-1.87 ; \mathrm{P}=0.126) .{ }^{21} \mathrm{In}$ the present meta-analysis, we found that using the HR from the model unadjusted for fasting triglyceride concentration did not change the overall risk estimate (RR, 1.04; 95\% CI: 0.99-1.10; $\mathrm{I}^{2}=48.3 \%$, $\mathrm{P}=0.060$ ). Furthermore, $\mathrm{Li}$ et al reported that the association was significant in CAD patients with medication alone but not in those with percutaneous coronary intervention (PCI) or coronary artery bypass grafting $(\mathrm{CABG}) .{ }^{21} \mathrm{We}$ assessed the risk estimates in these 2 subgroups and the results essentially remained the same. Sensitivity analysis according to type of ELISA kit used for PCSK9 measure- ment also did not change the results (Table 2). In addition, exclusion of any single study did not materially alter the combined estimate. The combined RR ranged from 1.008 to 1.082 , and all the $95 \% \mathrm{CI}$ included 1, suggesting that the association between PCSK 9 and the risk of CVD events was not statistically significant.

\section{Publication Bias}

Although the funnel plot was slightly asymmetric, after using the trim-and-fill method, visual inspection of the Begg funnel plot did not identify substantial asymmetry (Figure 4). In addition, there was no evidence of publication bias (Begg test, $\mathrm{P}=0.764$; Egger test, $\mathrm{P}=0.205$ ).

\section{Discussion}

To our knowledge, this is the first meta-analysis of prospective studies to summarize the evidence of the association between circulating PCSK9 concentration and the risk of CVD events. Circulating PCSK9 as a continuous variable was not significantly associated with the risk of CVD events. Moreover, subgroup and sensitivity analysis did not materially change the results. 


\begin{tabular}{|c|c|c|c|c|c|c|}
\hline & No. studies & RR & Low $95 \% \mathrm{Cl}$ & High $95 \% \mathrm{Cl}$ & $I^{2}(\%)$ & $P$ value \\
\hline Overall & 7 & 1.03 & 0.98 & 1.09 & 37.9 & 0.127 \\
\hline \multicolumn{7}{|l|}{ Stratified analysis } \\
\hline \multicolumn{7}{|l|}{ Mean age at baseline (years) } \\
\hline$\leq 60$ & 3 & 1.08 & 0.96 & 1.20 & 76.9 & 0.013 \\
\hline$>60$ & 4 & 1.03 & 0.97 & 1.10 & 1.0 & 0.400 \\
\hline \multicolumn{7}{|l|}{ Sample size } \\
\hline$<1,000$ & 3 & 1.04 & 0.83 & 1.25 & 29.1 & 0.238 \\
\hline$>1,000$ & 4 & 1.08 & 1.00 & 1.15 & 32.2 & 0.219 \\
\hline \multicolumn{7}{|l|}{ Follow-up } \\
\hline$\leq 4$ years & 4 & 1.01 & 0.89 & 1.14 & 24.1 & 0.267 \\
\hline$>4$ years & 3 & 1.08 & 1.00 & 1.17 & 32.0 & 0.220 \\
\hline \multicolumn{7}{|l|}{ Pre-existing disease } \\
\hline CAD & 3 & 1.10 & 1.00 & 1.24 & 0.0 & 0.566 \\
\hline No CAD & 4 & 1.08 & 0.98 & 1.18 & 43.0 & 0.135 \\
\hline \multicolumn{7}{|l|}{ Statin status } \\
\hline Statin used & 3 & 1.17 & 0.97 & 1.41 & 23.6 & 0.27 \\
\hline No statin therapy & 4 & 1.02 & 0.96 & 1.08 & 6.4 & 0.361 \\
\hline \multicolumn{7}{|l|}{ Sensitivity analysis } \\
\hline \multicolumn{7}{|l|}{ Werner et al $(2014)^{20}$ model } \\
\hline Unadjusted for fasting triglyceride & 7 & 1.04 & 0.99 & 1.10 & 48.3 & 0.060 \\
\hline Adjusted for fasting triglyceride & 7 & 1.05 & 0.99 & 1.11 & 52.1 & 0.041 \\
\hline \multicolumn{7}{|l|}{ Li et al $(2015)^{21}$ model } \\
\hline $\mathrm{PCl} / \mathrm{CABG}$ & 7 & 1.04 & 0.98 & 1.10 & 50.3 & 0.050 \\
\hline Medication alone & 7 & 1.04 & 0.99 & 1.10 & 46.1 & 0.072 \\
\hline \multicolumn{7}{|l|}{ ELISA kit used } \\
\hline R\&D systems & 4 & 1.01 & 0.96 & 1.08 & 6.4 & 0.361 \\
\hline Cyclex Japan & 2 & 0.86 & 0.25 & 3.00 & 58.4 & 0.121 \\
\hline
\end{tabular}

CABG, coronary artery bypass grafting; $\mathrm{PCl}$, percutaneous coronary intervention. Other abbreviations as in Table 1.

The methodological discrepancies, for example, sample size, duration of follow-up, and other aspects of the included studies may at least partially explain the negative results. Further, fasting status and type of blood sample (serum or plasma) also differed across the studies, resulting in a large range of mean PCSK9 $(94.3-546.5 \mathrm{ng} / \mathrm{mL}) .^{24,20}$

Differences in treatment regimen may have also contributed to the different results. Plasma PCSK9 predicted CVD events in CAD patients with medication alone but not in those with PCI/CABG treatment. ${ }^{21}$ Another study observed a significant association between PCSK9 and CVD risk in patients treated with low-dose but not high-dose atorvastatin. ${ }^{19}$ Statins can upregulate PCSK9 expression and modify the association between PCSK9 concentration and CVD risk. ${ }^{7,826}$ This upregulation of PCSK9 has the potential to limit the efficacy of statin-induced LDL-C reduction. ${ }^{27,28}$ PCSK9 binds to LDL-R and directs it toward lysosomal degradation rather than to normal recycling.29,30 Hence, inhibiting PCSK9 is a logical strategy to enhance statin-induced LDL-C reduction to decrease cardiovascular risk. ${ }^{31}$ The PCSK9 monoclonal antibody is of great interest because it blocks binding to LDL-R via an allosteric mechanism. ${ }^{32}$ PCSK9 inhibitors have been found to reduce plasma LDL-C in some early-phase clinical trials, ${ }^{9,10}$ but it remains unknown whether the reduced LDL-C induced by PCSK9 inhibitors can lower CVD mortality in the long term.

Recently, there has been increasing interest in the role of PCSK 9 variants in lipid homeostasis and the pathogenesis

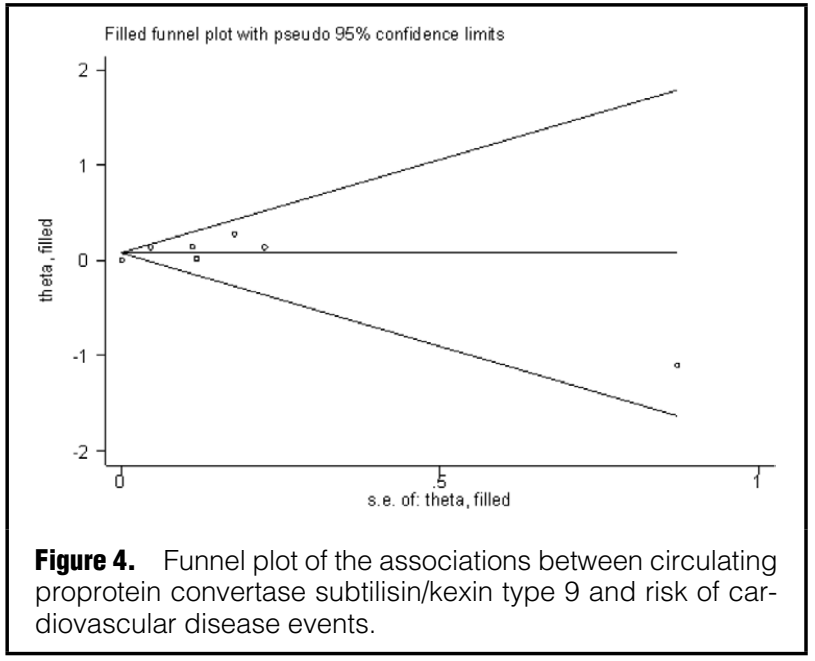

of CAD. A linear relationship was observed between PCSK9 variants and LDL-C or CAD risk in Mendelian randomized studies. Gain-of-function mutation of PCSK 9 (E670G) was associated with increased LDL-C and severity of CAD hypercholesterolemia, ${ }^{33-35}$ whereas lossof-function variants (C679X, Y142X, and R46L) were associated with reduced mean LDL-C and CAD risk. ${ }^{6}$ Furthermore, clinical trials have shown that inhibition of 
PCSK9 by a monoclonal antibody significantly reduced LDL-C and reduced the incidence of cardiovascular events. ${ }^{9,10}$ This suggests that the effect of PCSK9 variants or PCSK9 inhibitors on CVD risk is mainly due to its regulation of LDL-C. The negative results of the present meta-analysis also indicate that there may be no pleiotropic effect of $P C S K 9$ variants and level on CVD risk beyond LDL-C. No study, however, has simultaneously investigated the effect of PCSK 9 variants on circulating PCSK9 level and of genotype-phenotype interaction on the risk of CVD events. Because genotype distribution differs with ethnicity, the association between circulating PCSK9 and the risk of CVD events might be affected by the prevalence of PCSK9 polymorphisms. Further studies are needed in order to test this hypothesis.

The present study has several limitations. First, we noted substantial heterogeneity among the included studies, which may affect the interpretation of the results. The between-study heterogeneity may be influenced differing subject characteristics. Despite our efforts to identify the sources of heterogeneity on stratified and sensitivity analyses, the heterogeneity was not explained entirely. Second, uncontrolled or unmeasured risk factors may potentially introduce bias. Although all the included studies were adjusted for a group of conventional risk factors, the possibility of residual confounding cannot be completely ruled out, because these risk factors do not explain all of the risk of CVD events. Furthermore, the influencing factors of circulating PCSK9 and the correlations between PCSK9 and other risk factors differed between studies. In addition, because the distribution of circulating PCSK 9 was skewed in some studies, PCSK9 was log transformed in those studies and the combined risk estimates included both logtransformed and non-transformed HR. Finally, although we used broad inclusion criteria to minimize selection bias, and confirmed that this was unlikely on statistical analysis, the possibility cannot be completely ruled out. The capacity to detect publication bias is reduced when meta-analyses are based on a relatively small number of included studies. ${ }^{17,18}$ Selective reporting also cannot be excluded.

\section{Conclusions}

Although PCSK9 is a target for LDL-C reduction, its circulating level as a continuous variable is not associated with the risk of cardiovascular events. It seems that there is no pleiotropic effect of PCSK9 on CVD risk. A welldesigned multicenter study with standardized methodologies is needed to clarify whether PCSK9 is a biomarker for cardiovascular risk.

\section{Acknowledgments}

This work was supported by grants from the National Natural Science Foundation of China (81402672) and the Guangdong Provincial Medical Research Fund (B2014356).

\section{Disclosures}

The authors declare no conflicts of interest.

\section{References}

1. Levy E, Ben Djoudi Ouadda A, Spahis S, Sane AT, Garofalo C, Grenier E, et al. PCSK9 plays a significant role in cholesterol homeostasis and lipid transport in intestinal epithelial cells. Atherosclerosis 2013; 227: 297-306.

2. Lagace TA, Curtis DE, Garuti R, McNutt MC, Park SW, Prather HB, et al. Secreted PCSK9 decreases the number of LDL receptors in hepatocytes and in livers of parabiotic mice. $J$ Clin Invest 2006; 116: 2995-3005.

3. Zhang DW, Lagace TA, Garuti R, Zhao Z, McDonald M, Horton $\mathrm{JD}$, et al. Binding of proprotein convertase subtilisin/kexin type 9 to epidermal growth factor-like repeat A of low density lipoprotein receptor decreases receptor recycling and increases degradation. J Biol Chem 2007; 282: 18602-18612.

4. Chernogubova E, Strawbridge R, Mahdessian H, Malarstig A, Krapivner S, Gigante B, et al. Common and low-frequency genetic variants in the PCSK9 locus influence circulating PCSK9 levels. Arterioscler Thromb Vasc Biol 2012; 32: 1526-1534.

5. Abifadel M, Varret M, Rabes JP, Allard D, Ouguerram K, Devillers $\mathrm{M}$, et al. Mutations in PCSK9 cause autosomal dominant hypercholesterolemia. Nat Genet 2003; 34: 154-156.

6. Cohen JC, Boerwinkle E, Mosley TH Jr, Hobbs HH. Sequence variations in PCSK9, low LDL, and protection against coronary heart disease. N Engl J Med 2006; 354: 1264-1272.

7. Careskey HE, Davis RA, Alborn WE, Troutt JS, Cao G, Konrad RJ. Atorvastatin increases human serum levels of proprotein convertase subtilisin/kexin type 9. J Lipid Res 2008; 49: 394-398.

8. Welder G, Zineh I, Pacanowski MA, Troutt JS, Cao G, Konrad RJ. High-dose atorvastatin causes a rapid sustained increase in human serum PCSK9 and disrupts its correlation with LDL cholesterol. J Lipid Res 2010; 51: 2714-2721.

9. Sabatine MS, Giugliano RP, Wiviott SD, Raal FJ, Blom DJ, Robinson J, et al. Efficacy and safety of evolocumab in reducing lipids and cardiovascular events. N Engl J Med 2015; 372: $1500-1509$

10. Robinson JG, Farnier M, Krempf M, Bergeron J, Luc G, Averna $\mathrm{M}$, et al. Efficacy and safety of alirocumab in reducing lipids and cardiovascular events. N Engl J Med 2015; 372: 1489-1499.

11. Stroup DF, Berlin JA, Morton SC, Olkin I, Williamson GD, Rennie D, et al. Meta-analysis of observational studies in epidemiology: A proposal for reporting. Meta-analysis Of Observational Studies in Epidemiology (MOOSE) group. JAMA 2000; 283: $2008-2012$.

12. Ridker PM, Rifai N, Bradwin G, Rose L. Plasma proprotein convertase subtilisin/kexin type 9 levels and the risk of first cardiovascular events. Eur Heart J 2016; 37: 554-560.

13. Walter SD, Cook RJ. A comparison of several point estimators of the odds ratio in a single $2 \times 2$ contingency table. Biometrics 1991; 47: 795-811.

14. DerSimonian R, Laird N. Meta-analysis in clinical trials. Control Clin Trials 1986; 7: 177-188.

15. Riley RD, Higgins JP, Deeks JJ. Interpretation of random effects meta-analyses. $B M J$ 2011; 342: d549.

16. Higgins JP, Thompson SG, Deeks JJ, Altman DG. Measuring inconsistency in meta-analyses. BMJ 2003; 327: 557-560.

17. Egger M, Davey Smith G, Schneider M, Minder C. Bias in metaanalysis detected by a simple, graphical test. BMJ 1997; 315: 629-634.

18. Begg CB, Mazumdar M. Operating characteristics of a rank correlation test for publication bias. Biometrics 1994; 50: 1088-1101.

19. Huijgen R, Boekholdt SM, Arsenault BJ, Bao W, Davaine JM, Tabet F, et al. Plasma PCSK9 levels and clinical outcomes in the TNT (Treating to New Targets) trial: A nested case-control study. J Am Coll Cardiol 2012; 59: 1778-1784.

20. Werner C, Hoffmann MM, Winkler K, Bohm M, Laufs U. Risk prediction with proprotein convertase subtilisin/kexin type 9 (PCSK9) in patients with stable coronary disease on statin treatment. Vascul Pharmacol 2014; 62: 94-102.

21. Li JJ, Li S, Zhang Y, Xu RX, Guo YL, Zhu CG, et al. Proprotein convertase subtilisin/kexin type 9, C-reactive protein, coronary severity, and outcomes in patients with stable coronary artery disease: A prospective observational cohort study. Medicine 2015; 94: e2426.

22. Zhu YM, Anderson TJ, Sikdar K, Fung M, McQueen MJ, Lonn EM, et al. Association of proprotein convertase subtilisin/kexin type 9 (PCSK9) with cardiovascular risk in primary prevention. Arterioscler Thromb Vasc Biol 2015; 35: 2254-2259.

23. Gencer B, Montecucco F, Nanchen D, Carbone F, Klingenberg $\mathrm{R}$, Vuilleumier N, et al. Prognostic value of PCSK9 levels in patients with acute coronary syndromes. Eur Heart J 2016; 37: $546-553$.

24. Leander K, Malarstig A, Van't Hooft FM, Hyde C, Hellenius ML, Troutt JS, et al. Circulating proprotein convertase subtili$\sin /$ kexin type 9 (PCSK9) predicts future risk of cardiovascular events independently of established risk factors. Circulation 2016; 133: $1230-1239$.

25. Rogacev KS, Heine GH, Silbernagel G, Kleber ME, Seiler S, 
Emrich I, et al. PCSK9 plasma concentrations are independent of GFR and do not predict cardiovascular events in patients with decreased GFR. PLoS One 2016; 11: 0146920.

26. Berge KE, Ose L, Leren TP. Missense mutations in the PCSK9 gene are associated with hypocholesterolemia and possibly increased response to statin therapy. Arterioscler Thromb Vasc Biol 2006; 26: $1094-1100$

27. Dubuc G, Chamberland A, Wassef H, Davignon J, Seidah NG, Bernier L, et al. Statins upregulate PCSK9, the gene encoding the proprotein convertase neural apoptosis-regulated convertase-1 implicated in familial hypercholesterolemia. Arterioscler Thromb Vasc Biol 2004; 24: 1454-1459.

28. Jeong HJ, Lee HS, Kim KS, Kim YK, Yoon D, Park SW. Steroldependent regulation of proprotein convertase subtilisin/kexin type 9 expression by sterol-regulatory element binding protein- 2 . J Lipid Res 2008; 49: 399-409.

29. Lambert G. Unravelling the functional significance of PCSK9. Curr Opin Lipidol 2007; 18: 304-309.

30. Lambert G, Charlton F, Rye KA, Piper DE. Molecular basis of PCSK9 function. Atherosclerosis 2009; 203: $1-7$.

31. Steinberg D, Witztum JL. Inhibition of PCSK9: A powerful weapon for achieving ideal LDL cholesterol levels. Proc Natl
Acad Sci USA 2009; 106: 9546-9547.

32. Fitzgerald K, Frank-Kamenetsky M, Shulga-Morskaya S, Liebow A, Bettencourt BR, Sutherland JE, et al. Effect of an RNA interference drug on the synthesis of proprotein convertase subtilisin/kexin type 9 (PCSK9) and the concentration of serum LDL cholesterol in healthy volunteers: A randomised, single-blind, placebo-controlled, phase 1 trial. Lancet 2014; 383: 60-68.

33. Huang CC, Fornage M, Lloyd-Jones DM, Wei GS, Boerwinkle E, Liu K. Longitudinal association of PCSK9 sequence variations with low-density lipoprotein cholesterol levels: The Coronary Artery Risk Development in Young Adults Study. Circ Cardiovasc Genet 2009; 2: 354-361.

34. Slimani A, Harira Y, Trabelsi I, Jomaa W, Maatouk F, Hamda $\mathrm{KB}$, et al. Effect of E670G polymorphism in PCSK9 gene on the risk and severity of coronary heart disease and ischemic stroke in a Tunisian cohort. J Mol Neurosci 2014; 53: 150-157.

35. Hsu LA, Teng MS, Ko YL, Chang CJ, Wu S, Wang CL, et al. The PCSK9 gene E670G polymorphism affects low-density lipoprotein cholesterol levels but is not a risk factor for coronary artery disease in ethnic Chinese in Taiwan. Clin Chem Lab Med 2009; 47: 154-158. 